\title{
KOMPLEKSITAS PRANATA SOSIAL MASYARAKAT BATAK TOBA DALAM \\ CERPEN "BERAKHIR SEBELUM TIBA DI UJUNG JALAN" KARYA MEINA HUTABARAT
}

\author{
Nur Sitha Afrilia \\ Program Studi Magister Ilmu Susastra \\ Universitas Diponegoro \\ Author correspondence : nursithaafrilia@students.undip.ac.id
}

\begin{abstract}
Abstrak
Cerita pendek (cerpen) merupakan produk karya sastra yang tidak dapat dipungkiri hakikatnya sebagai hasil refleksi pengarang terhadap dinamika kehidupan yang ada di sekitarnya. Termasuk di dalamnya adalah penggambaran kondisi sosial-budaya yang dinarasikan secara fiktif, namun tetap terikat pada koridor kebudayaan yang berlaku. Salah satu wujud dari penggambaran kondisi tersebut dapat dilihat pada narasi kompleksitas pranata sosial suku Batak Toba dalam cerpen "Berakhir Sebelum Tiba di Ujung Jalan” karya Meina Hutabarat. Dinamika kehidupan yang diangkat dalam cerpen tersebut berkaitan erat dengan realita sosial dalam tataran kebudayaan yang berlaku di kelompok masyarakat Batak Toba hingga saat ini. Keterkaitan itulah yang kemudian menjadi titik pijak penulis dalam menganalisis unsur sosiologi sastra dalam objek, untuk kemudian dijadikan dasar kesimpulan akhir. Kesimpulan tersebut diambil melalui studi kepustakaan dan secara umum hasil dari penelitian ini adalah penegasan bahwa sebagai hasil refleksi, karya sastra juga dapat dijadikan medium pemberontakan implisit terhadap isu sosial-budaya yang terjadi.
\end{abstract}

Kata kunci: Batak Toba, Pranata Sosial, Sosiologi Sastra dan Cerpen.

\begin{abstract}
Short story is a product of literary works that can not be denied as a result of the author's reflection on the dynamics of life around him. This includes depictions of socio-cultural conditions that are narrated fictitiously, but are still bound by the prevailing cultural corridors. A form of the depiction of these conditions can be seen in the narrative of the complexity of the Batak Toba (Tobanese) social institutions in the short story "Berakhir Sebelum Tiba di Ujung Jalan" by Meina Hutabarat. The dynamics of life were raised in the short story are closely related to social reality in the level of culture that prevails in Tobanese society until now. That linkage then becomes the starting point of the writer in analyzing the elements of literary sociology in the object that will use to be a basic for the final conclusion. The conclusion was drawn through a literature study and the results of this study are the assertion that as a result of reflection and it can also be used as an implicit rebellion medium against socio-cultural issues that occur.
\end{abstract}

Keyword: Bataknese (Toba), Social Institution, Sociology of Literature and Short Story. 


\section{Pendahuluan}

Setiap kelompok masyarakat memiliki budayanya masing-masing. Budaya tersebut melahirkan dinamika kehidupan yang kemudian menjadi pembeda khusus dengan kelompok lain. Termasuk budaya yang dimiliki oleh masyarakat dari suku Batak dengan rumpun Toba. Kompleksitas aturan adat yang masih dijaga dengan baik melahirkan daya tarik tersendiri bagi penulis. Hal-hal yang mencerminkan kompleksitas tersebut tidak selalu ditunjukan melalui literatur sejarah maupun antropologi. Beberapa karya sastra pun lahir dengan embrio utama yang berwujud hierarki kehidupan dan dinamika kebudayaan suku Batak Toba. Salah satu karya sastra yang mengangkat isu budaya dari suku Batak Toba adalah cerpen "Berakhir Sebelum Tiba di Ujung Jalan" (yang selanjutnya akan disebut "BSTJ") karya Meina Hutabarat. Permasalahan sinamot yang berujung pada kegagalan pernikahan tokoh dalam cerita tersebut menjadi salah satu isu yang menurut penulis layak untuk dikaji dengan pendekatan sosiologi sastra.

Sinamot secara umum dapat diartikan sebagai mahar atau yang lebih eksplisit juga bisa dimaknai sebagai uang tebus untuk perempuan yang harus diberikan oleh pihak mempelai laki-laki. Jumlah sinamot sendiri memiliki standar khusus yang disesuaikan dengan latar belakang sosial calon mempelai perempuan, yang kemudian juga diselaraskan dengan permintaan pihak keluarga besar. Jadi, dalam tradisi Batak Toba, urusan mahar tidak hanya menjadi permasalahan internal orang tua kedua belah pihak, melainkan keluarga besar dari pihak perempuan juga. Termasuk di dalamnya adalah Paman dari calon mempelai perempuan yang diwajibkan untuk mendapat bagian dari mahar tersebut. Aturan yang demikian itulah, yang kemudian menjadi salah satu faktor yang menurut penulis adalah bagian dari kompleksitas pranata sosial yang berlaku di lingkungan masyarakat Batak Toba.

Berdasarkan pada latar belakang di atas, maka, dalam artikel ini penulis akan menjelaskan wujud kompleksitas pranata sosial masyarakat Batak Toba dalam cerpen BSTJ dari sudut tinjauan sosiologi sastra. Hasil dari penjelasan tersebut secara otomatis menjadi jawaban dari rumusan masalah yang mempertanyakan perihal "bagaimana" kompleksitas pranata sosial yang berlaku di lingkup internal masyarakat Batak Toba dalam objek kajian yang ditinjau dari segi sosiologi sastra. Kemudian, terkait dengan metode penelitian, penulis memilih untuk menggunakan metode kontekstual pada artikel ini. Metode tersebut menggabungkan analisis unsur-unsur teks dengan unsur-unsur yang relevan di luar teks. Pemilihan metode tersebut didasari oleh gagasan Behrendt (dalam Ratna) yang menyatakan bahwa, "simply an analysis of a text ... that helps us to assess that text within the context of its historical and cultural setting, but also in terms of its textuality -or the qualities that characterize the text as a text." (https://media.neliti.com/media/publications/90484ID-none.pdf yang diakses pada 12 Juni 2020). Penelitian dengan metode ini bisa juga diartikan sebagai penelitian yang menggunakan metode kepustakaan atau library research. Berpijak pada penjelasan tersebut, maka, penulis juga menegaskan bahwa penelitian ini juga bersifat deksriptifkualitatif karena penelitian bertumpu pada studi kepustakaan dengan fokus analisis teks (objek) dengan sumber-sumber referensi yang berkaitan dengan hierarki kehidupan masyarakat suku Batak Toba. Khususnya hierarki yang bersinggungan dengan pranata sosial masyarakat dalam tataran perkawinan.

Sebelum masuk dalam pembahasan inti, maka perlu dipahami terlebih dulu bahwa pranata sosial menurut Koentjaraningrat (1974) adalah suatu sistem tata kelakuan dan hubungan yang berpusat pada aktivitas-aktivitas untuk memenuhi kompleks-kompleks kebutuhan khusus dalam kehidupan masyarakat. Salah satu kompleks kebutuhan khusus dalam kehidupan masyarakat menurut penulis adalah aturan-aturan yang mengikat urusan perkawinan yang berlaku dalam sebuah 
kelompok masyarakat tertentu. Oleh karena itu, berpijak pada hasil penalaran dari pendapat Koentjaraningrat yang bersifat umum, maka penulis dalam analisis ini akan membatasi pembahasan pada konteks perkawinan yang berlaku di masyarakat suku Batak Toba. Pembatasan tersebut dilatarbelakangi oleh objek material yang berupa cerpen dengan judul "Berakhir Sebelum Tiba di Ujung Jalan" karya Meina Hutabarat. Cerpen sendiri menurut Tarigan (2011) adalah cerita pendek yang merupakan suatu kebulatan ide. Dalam kesingkatan dan kepadatannya itu, sebuah cerpen lengkap, bulat, dan singkat. Artinya, semua bagian cerpen harus terikat pada suatu kesatuan jiwa, yaitu pendek, padat, dan lengkap; tidak ada bagian yang tidak penting.

Berpijak pada penjelasan tersebut, maka penulis menyimpulkan bahwa latar belakang masyarakat Toba beserta aturan adat yang menyertainya adalah kesatuan unsur yang saling berkaitan dalam pembentukan struktur cerpen, baik dari segi unsur intrinsik maupun unsur ekstrinsiknya. Dinamika kebudayaan yang kompleks menjadikan penulis yakin untuk memilih tinjauan sosiologi sastra sebagai pendekatan dalam analisis ini. Sosiologi sastra sendiri menurut Damono (2002) adalah studi objektif dan ilmiah tentang manusia dalam masyarakat, telaah tentang lembaga dan proses sosial. Berkaitan dengan hal tersebut, perlu diketahui juga bahwa Pardosi (2008) berpendapat, "perkawinan orang Batak pada umumnya merupakan suatu pranata yang tidak hanya mengikat seorang laki-laki dan perempuan melainkan dua keluarga besar, yaitu kerabat dari laki-laki (paranak) dan kerabat dari perempuan (parboru). Kemudian, Bruner (1996) berpendapat bahwa, "sistem kekerabatan orang Batak adalah patrilineal (menurut garis keturunan ayah). Garis keturunan ayah akan diteruskan oleh anak laki-lakinya dan akan menjadi punah jika tidak memiliki anak lakilaki, sedangkan boru (anak perempuan) akan menciptakan hubungan besan melalui pernikahannya dengan laki-laki dari kelompok patrilineal lain. Kompleksitas dari sistem perkawinan itu diangkat dalam cerpen BSTJ.

\section{Pembahasan}

"Aku" dan "Martin" adalah tokoh sentral dalam cerpen tersebut. Keduanya diceritakan oleh pengarang sebagai sepasang kekasih yang pada akhirnya gagal menikah. Kegagalan dari pernikahan tersebut diakibatkan oleh adanya pelanggaran kesepakatan hasil marhata sinamot ${ }^{l}$ antara pihak keluarga tokoh aku (perempuan) dan Martin. Hal tersebut dibuktikan dengan kutipan berikut,

“.............. 'Sampaikan terima kasihku pada Tulang' ${ }^{2}$ ya, Pak. Terima kasih sudah ikut serta menghancurkan rencana pernikahan dan hubunganku dengan Martin.’ ucapku sarkas.”

“Apa maksudmu, Boru?" tanya bapak dengan khawatir.

"Martin sudah mengakhiri hubungan kami. Tidak ada lagi rencana pernikahan. Silakan bapak dan mamak beritahukan pada seluruh keluarga..........."

Dari kutipan di atas, dapat diketahui bahwa salah satu penyebab kegagalan pernikahan tokoh "aku" dan "Martin" adalah keikutsertaan pihak keluarga besar dalam menentukan jumlah uang

${ }^{1}$ Marhata sinamot merupakan tahapan yang harus dilalui oleh dua belah pihak keluarga Batak yang akan berbesan. Lazimnya, marhata sinamot atau diskusi soal besaran uang yang harus dibayarkan oleh pihak laki-laki pada keluarga perempuan ini dilaksanakan bersamaan dengan marhori-hori dinding atau tahap awal dari pertemuan dua belah pihak keluarga.

\footnotetext{
${ }^{2}$ Sebutan untuk Paman dalam Bahasa Batak

${ }^{3}$ Sebutan untuk anak perempuan dalam bahasa Batak
} 
sinamot ${ }^{4}$. Padahal sebelumnya, jumlah sinamot sudah disepakati oleh kedua belah pihak. Namun, ada pelanggaran kesepakatan yang disebabkan oleh keikutsertaan tokoh "Tulang" (paman) dari tokoh "aku". Hal tersebut dibuktikan dengan kutipan berikut,

“.......... 'Tulangmu bilang sinamot itu terlalu kecil untuk wanita sepertimu."

“Wanita sepertiku?" tanyaku tidak mengerti.

"Kamu berpendidikan tinggi, punya karir bagus, masa hanya dihargai tiga puluh lima juta? Harusnya bisa lebih dari itu." ucap Bapak.

Kutipan dari ucapan tokoh Bapak dalam penggalan cerpen tersebut seolah menunjukan adanya kesan eksklusivitas diri karena latar belakang pendidikan dan pekerjaan yang dimiliki oleh tokoh "aku". Eksklusivitas tersebut kemudian dijadikan alibi untuk meminta kenaikan jumlah uang sinamot kepada pihak keluarga tokoh "Martin".

Memang tidak dapat dipungkiri bahwa keberadaan sinamot dalam pranata sosial yang khususnya berkaitan dengan urusan perkawinan dalam masyarakat Batak Toba ibarat momok tersendiri. Terlebih bagi kaum laki-laki, jika tidak memperhatikan faktor finansial dengan baik, maka bisa saja perjalanannya dalam menuju jenjang pernikahan akan terhambat. Selain sinamot, masyarakat Batak juga memiliki serangkaian prosesi pernikahan yang rumit dan memerlukan banyak biaya. Apalagi jika pesta pernikahan tersebut harus benar-benar pakem mengikuti tradisi yang berlaku.

Kebanyakan orang dari suku Batak Toba saat ini menyederhanakan proses pernikahan serta menyesuaikannya dengan hal-hal yang modern. Namun, meskipun begitu, tidak sedikit orang yang tetap paten menjalankan tradisi, termasuk untuk menggelar pesta dengan menyembelih kerbau. Orang yang masuk dalam kategori paten melaksanakan tradisi biasanya tinggal di pedesaan yang jauh dari kota dan masih kental aturan adatnya. Jadi, tidak peduli risiko-risiko dari sebuah tradisi yang akan berimbas pada kondisi finansial, mereka akan tetap menjalankan sebagaimana mestinya. Pernyataan tersebut sesuai dengan kutipan berikut,

“Aku mulai benci adat Batak.” gumamku.

"Bukan. Bukan adatnya yang salah. Tetapi orang-orang yang menggunakannya untuk menaikkan harkat dan martabat keluarga sehingga tidak peduli kalau harus mengorbankan orang lain. "

Dua kutipan di atas jelas menunjukkan situasi bahwa sebenarnya, masyarakat Batak Toba sangat menjunjung tinggi budaya dan tradisi yang diturunkan oleh leluhurnya. Namun sayangnya, kepatuhan terhadap budaya dan tradisi tersebut tidak diimbangi dengan kesadaran yang realistis terhadap situasi dan kondisi yang ada dalam internal keluarganya.

Menurut pendapat penulis, sikap yang berani menjunjung tinggi adat-istiadat leluhur merupakan sikap yang wajib diapresiasi. Namun, terlalu kaku dengan mengabaikan faktor internal keluarga yang berupa kondisi finansial dan sejenisnya demi memenuhi kepentingan adat juga bukan

\footnotetext{
${ }^{4}$ Sinamot adalah mahar dalam bentuk uang yang diberikan pihak laki-laki pada perempuan. Umumnya, nominal sinamot didasarkan pada jenjang pendidikan dan karir perempuan. Semakin tinggi, maka semakin mahal. Namun pada perkembangannya, nominal tersebut tetap menjadi kesepakatan kedua belah pihak keluarga.
} 
hal yang bijak. Cerpen BSTJ bagi penulis merupakan media yang digunakan pengarang untuk mengajak masyarakat lebih realistis. Artinya, tidak memaksakan suatu kehendak yang sekiranya memberatkan langkah ke depannya. Bukan berarti bahwa cerpen ini simbol perlawanan terhadap pranata sosial yang berlaku, namun justru, secara implisit pengarang berupaya untuk lebih solutif dan bijak dalam menghadapi permasalahan yang berkaitan dengan adat-istiadat.

Tokoh "Martin" bagi penulis adalah media yang digunakan oleh pengarang untuk merepresentasikan pihak yang kurang solutif. Berbanding terbalik dengan tokoh "aku" yang berusaha bijak, tenang dan solutif dalam mencari jalan keluar dari permasalahan yang tengah melilit keduanya. Kegigihan tokoh "aku" dalam mencari solusi dapat dilihat dari upayanya menawarkan berbagai ide, termasuk menunda pernikahan dari 1 hingga 2 tahun lagi. Selain itu, kegigihan tersebut juga ditunjukan melalui penjelasan terkait upaya yang akan dia ambil untuk meyakinkan dan mencabut permintaan bapak. Permintaan yang sebenarnya sudah masuk dalam kategori pelanggaran kesepakatan awal. Berikut adalah salah satu bukti dari kegigihan tersebut,

“.......... 'Aku akan bicarakan lagi dengan bapak. Jangan khawatir, aku bisa membujuknya. Bilang sama Amangboru, tidak usah turuti semua yang Bapak minta. Kesepakatan kita tetap seperti kesepakatan awal.

Berbanding terbalik dengan Martin yang justru memilih untuk mengakhiri hubungannya dengan tokoh "Aku" setelah mempertimbangkan berbagai risiko jika hubungan mereka tetap dilanjutkan.

Sikap yang diambil oleh tokoh "Martin" adalah contoh dari imbas kompleksitas pranata sosial yang berlaku di masyarakat Batak Toba. Tidak adanya kesepakatan dalam pelaksanaan tata upacara adat perkawinan hingga tidak adanya titik temu dalam menyepakati jumlah uang sinamot adalah hal yang pada akhirnya, sering menjadi alasan para laki-laki Batak untuk lebih memilih menikah dengan perempuan di luar sukunya. Meski konsekuensi dari hal tersebut adalah harus mengadati calon istrinya agar masuk dalam suku dan memiliki marga.

\section{Simpulan}

Cerpen BSTJ adalah cerpen yang mengangkat dampak kompleksitas pranata sosial masyarakat Batak Toba dalam tataran perkawinan. Keikutsertaan keluarga besar (di luar orang tua inti) yang direpresentasikan tokoh Tulang dalam menentukan sinamot dan hal-hal yang berkaitan dengan pesta pernikahan adalah bukti bahwa, kekerabatan dalam hierarki keluaga Batak Toba sangat dijunjung tinggi. Dari segi sosial, bagi penulis cerpen ini secara eksplisit menunjukan salah satu bukti bahwa setiap kelompok masyarakat memiliki kompleksitas khusus yang terikat dalam aturanaturan adatnya. Namun di sisi lain, penulis merasa bahwa pengarang memiliki misi yang secara implisit ditunjukkan melalui sikap tokoh "aku" yang menyayangkan kompleksitas adat Batak. Bukan berarti menentang atau tidak setuju, namun melalui penjelasan tokoh "Martin" yang kurang bijak adalah sikap masyarakat dalam menjalankan serangkaian adat tersebut. Tidak ada yang keliru dari sebuah tradisi, adat dan budaya yang telah diturunkan dari leluhur dan dipertahankan dalam sebuah masyarakat. Sebab, semua tradisi pasti mempertimbangkan hal-hal yang baik dan diyakini juga akan menjadi jembatan kebaikan bagi para penganutnya. Namun, semua itu bisa berbanding terbalik jika tidak diimbangi dengan sikap yang bijaksana dari para pelakunya. 
KLITIKA: Jurnal Ilmiah Pendidikan Bahasa dan Sastra Indonesia.

Volume 2, Nomor 1, 2020, pp 39-44

\section{Daftar Pustaka}

Asmarani, Ratna. 2016. Analisis Keberadaan Emma Lou dalam "The Blacker The Berry" karya Wallace Thurman. https://media.neliti.com/media/publications/90484-ID-none.pdf(diakses pada 12 Juni 2020)

Bruner, Edward. 1996. Kerabat dan Bukan Kerabat. Pokok-Pokok Antropologi Budaya. TO Ihromi (ed). Jakarta: Yayasan Obor Indonesia.

Damono, Sapardi Djoko. 2002. Pedoman Penelitian Sastra. Jakarta: Pusat Bahasa Departemen Pendidikan Nasional.

Hutabarat, Meina. 2017. Berakhir Sebelum Tiba di Ujung Jalan. https://www.seeword.com/berakhir-sebelumtiba-di-ujung-jalan. Diakses pada 10 April 2020.

Koentjaraningrat. 1974. Kebudayaan Mentaliet dan Pembangunan. Jakarta: Gramedia

Napitupulu, Paimin. 2008. Pedoman Praktis Upacara Adat Batak . Jakarta: Papas Sinar Sinanti.

Pardosi, Jhonson. 2008. Makna Simbolik Umpasa, Sinamot, dan Ulos pada Adat Perkawinan Batak Toba. Jurnal Ilmiah Bahasa dan Sastra,volume IV nomor 2, hal.105

Tarigan, H.G. 2011. Prinsip-Prinsip Dasar Sastra. Bandung: Angkasa Thahar 